\title{
Haemodynamics and gas exchange before and after coil embolization of pulmonary arteriovenous malformations
}

\author{
P. Andrivet*, F. Lofaso*, M-F. Carette**, J. Allegrini+, S. Adnot*
}

\begin{abstract}
Haemodynamics and gas exchange before and after coil embolization of pulmonary arteriovenous malformations. P. Andrivet, F. Lofaso, M-F. Carette, J. Allegrini, S. Adnot. CERS Journals Ltd 1995.

ABSTRACT: A complete description of haemodynamics and gas exchange before and after percutaneous coil embolization of multiple pulmonary arteriovenous malformations is reported, in a 45 year old woman with hereditary haemorrhagic telangiectasis (HHT). Before treatment, whilst the patient complained of severe dyspnoea during daily activities, an intrapulmonary shunt of $31 \%$ was measured (inert gas elimination technique), together with a cardiac output (thermodilution technique) of $12.4 \mathrm{~L} \cdot \mathrm{min}^{-1}$, resulting in a resting arterial oxygen tension $\left(\mathrm{Pa}_{\mathrm{a}} \mathrm{O}_{2}\right)$ of $8.53 \mathrm{kPa}$.

Effective occlusion of all visible pulmonary malformations resulted in a rapid and major improvement in exercise tolerance, whilst resting $\mathrm{P}_{\mathrm{a}}, \mathrm{O}_{2}$ remained almost unchanged. A second investigation performed 4 months after treatment revealed a persistent intrapulmonary shunt of $19 \%$, a cardiac output of $7.35 \mathrm{~L} \cdot \mathrm{min}^{-1}$, and a resting $P \mathrm{a}, \mathrm{O}_{2}$ of $10.53 \mathrm{kPa}$.

We conclude that major increases in cardiac output largely contribute to the maintenance of $P \mathrm{a}, \mathrm{O}_{2}$ in patients with multiple pulmonary arteriovenous malformations and intrapulmonary shunt. The benefit of coil embolization is due both to an improvement in arterial oxygenation and a normalization of cardiac output. Eur Respir J., 1995, 8, 1228-1230.
\end{abstract}

\begin{abstract}
*Service d'Explorations Fonctionnelles Respiratoires, and +Department de Cardiologie, Hôpital Henri Mondor, Créteil, France. **Service de Radiologie, Hôpital Tenon, Paris, France.
\end{abstract}

Correspondence: P. Andrivet

Service d'Explorations Fonctionnelles Respiratoires

Hôpital Henri Mondor

94010 Créteil

France.

Keywords: Embolization gas exchange

pulmonary arteriovenous malformation

Received: October 201994

Accepted after revision February 51995
Large or multiple pulmonary arteriovenous malformations (PAVM) may lead to severe and incapacitating hypoxaemia via right-to-left intrapulmonary shunts. Several reports have recently offered important clinical, gasometric and therapeutic insights into this problem [1-4]. However, a complete description and follow-up of the haemodynamic and gas exchange data, including assessment of the distribution of ventilation-perfusion ratios, has not previously been reported. The present case report describes how alterations of haemodynamics and gas exchange, observed in a 45 year old woman with hereditary haemorrhagic telangiectasia (HHT) and PAVM, were improved by therapeutic coil embolization.

\section{Case report}

A female patient was investigated for increasing dyspnoea, with major impairment of her daily activities. Questioning revealed that an elder brother underwent balloon embolization in 1985 for multiple PAVM. Physical examination at rest showed a mild tachypnoea (20 breaths. $\min ^{-1}$ ), with digital clubbing, and digital cyanosis was present whilst standing. The patient was unable to perform an exercise test of $1 \mathrm{~min}$ at a workload of $40 \mathrm{~W}$. No cutaneous telangiectasis was present, but a previous episode of epistaxis was related to the presence of nasal telangiectasis. Normal values for respiratory function tests were recorded (forced expiratory volume in one second (FEV1) $3.70 \mathrm{~L}, 126 \%$ of predicted value; forced vital capacity (FVC): $4.12 \mathrm{~L} ; 118 \%$ pred), and bidimensional echocardiography was normal. The chest radiograph showed multiple pulmonary shadows. The pulmonary angiogram showed eight arteriovenous malformations in the left lung and six in the right lung.

Percutaneous coil embolization of these malformations was achieved in three successive sessions. One month after the last embolization session, a noticeable improvement in the patient's respiratory symptoms was reported. Four months after the last embolization session, the patient was eupneic at rest, with a respiratory rate of 13 breaths $\cdot \mathrm{min}^{-1}$. Digital cyanosis had disappeared, and an exercise test at a workload of $60 \mathrm{~W}$ could be maintained during $5 \mathrm{~min}$. Blood gases drawn at the end of the exercise test showed an arterial oxygen tension $\left(\mathrm{Pa}_{\mathrm{a}, \mathrm{O}_{2}}\right)$ of 8.0 $\mathrm{kPa}$, an arterial oxygen saturation $\left(\mathrm{Sa}_{\mathrm{a}} \mathrm{O}_{2}\right)$ of $92 \%$ and an arterial carbon dioxide tension $\left(\mathrm{Pa}_{\mathrm{a}} \mathrm{O}_{2}\right)$ of $3.7 \mathrm{kPa}$.

Table 1 summarizes haemodynamic and gasometric data, including measurements of the distribution of ventilation-perfusion ratios assessed by the multiple inert gas elimination technique (MIGET) [5], as described previously [6], prior to and 134 days after the last coil embolization session. Minute ventilation was almost halved by the embolization procedure. Before embolization, 
Table 1. - Results obtained from right heart catheterization and multiple inert gas elimination technique prior to and after coil embolization of multiple arteriovenous malformations

\begin{tabular}{|c|c|c|}
\hline & $\begin{array}{c}\text { Before } \\
\text { treatment }\end{array}$ & $\begin{array}{c}\text { After } \\
\text { treatment }\end{array}$ \\
\hline$V^{\prime} \mathrm{E} \quad \mathrm{L} \cdot \mathrm{min}^{-1}$ & 18.3 & 10.9 \\
\hline$f \mathrm{R}$ breaths $\cdot \min ^{-1}$ & 20 & 13 \\
\hline Haemoglobin $\mathrm{g} \cdot \mathrm{L}^{-1}$ & 152 & 150 \\
\hline$f_{\mathrm{c}}$ beats $\cdot \mathrm{min}^{-1}$ & 120 & 80 \\
\hline $\mathrm{CI} \quad \mathrm{L} \cdot \mathrm{min}^{-1} \cdot \mathrm{m}^{-2}$ & 7.1 & 4.2 \\
\hline$P_{\mathrm{sa}} \mathrm{mmHg}$ & 105 & 90 \\
\hline$P_{\text {pa }} \mathrm{mmHg}$ & 14 & 15 \\
\hline$P$ pa,o $\mathrm{mmHg}$ & 6 & 5 \\
\hline Pra $\mathrm{mmHg}$ & 6 & 4 \\
\hline \multicolumn{3}{|c|}{ Blood gases during room air breathing } \\
\hline $\mathrm{pH}$ & 7.46 & 7.45 \\
\hline $\mathrm{Pa}, \mathrm{CO}_{2} \quad \mathrm{kPa}$ & 3.6 & 3.7 \\
\hline${\mathrm{Pa}, \mathrm{O}_{2}}^{2} \mathrm{kPa}$ & 8.5 & 10.5 \\
\hline$P_{\mathrm{v}, \mathrm{O}_{2}} \mathrm{kPa}$ & 5.3 & 5.9 \\
\hline$V^{\prime} \mathrm{O}_{2}, \mathrm{~m} \mathrm{~L} \cdot \mathrm{min}^{-1} \cdot \mathrm{m}^{-2}$ & 0.200 & 0.160 \\
\hline$T \mathrm{~L}, \mathrm{CO} \%$ pred & 63 & 73 \\
\hline \multicolumn{3}{|c|}{ Blood gases during $100 \%$ oxygen breathing } \\
\hline $\mathrm{pH}$ & 7.42 & 7.45 \\
\hline${\mathrm{Pa}, \mathrm{CO}_{2}}_{\mathrm{kPa}} \mathrm{ka}$ & 4.3 & 3.7 \\
\hline${\mathrm{Pa}, \mathrm{O}_{2}}^{2} \mathrm{kPa}$ & 32.1 & 49.3 \\
\hline$P_{\mathrm{v}, \mathrm{O}_{2}}^{-} \mathrm{kPa}$ & 7.2 & 7.9 \\
\hline $\mathrm{Da}-\mathrm{v}, \mathrm{O}_{2} \quad \mathrm{ml} \cdot \mathrm{L}^{-1}$ & 31 & 34 \\
\hline Oxygen shunt \% & 32 & 22 \\
\hline Inert gas shunt $\%$ & 31 & 19 \\
\hline Low $V^{\prime} \mathrm{A} / Q^{\prime}$ & 0 & 0 \\
\hline Mean $Q^{\prime}$ & 1.11 & 0.76 \\
\hline $\log \mathrm{SD} Q^{\prime}$ & 0.39 & 0.49 \\
\hline$V_{\mathrm{D}} / V_{\mathrm{T}} \quad \%$ & 39 & 41 \\
\hline Mean $V^{\prime}$ & 1.29 & 0.90 \\
\hline $\log \mathrm{SD} V^{\prime} \mathrm{A}$ & 0.38 & 0.38 \\
\hline
\end{tabular}

$V$ 'E: minute ventilation; $f_{\mathrm{R}}$ : respiratory frequency; $f_{\mathrm{c}}$ : heart rate; $\mathrm{CI}$ : cardiac index; $P_{\mathrm{sa}}$ : systemic artery pressure; $P$ pa: pulmonary artery pressure; $P$ pa,o: pulmonary artery occluded pressure; $P$ ra: right arterial pressure; $\mathrm{Pa}_{\mathrm{a}} \mathrm{O}_{2}$ : arterial oxygen tension; $\mathrm{Pa}_{\mathrm{a}} \mathrm{CO}_{2}$ : arterial carbon dioxide tension; $P \overline{\mathrm{v}}, \mathrm{O}_{2}$ : mixed venous oxygen tension; $V^{\prime} \mathrm{O}_{2}, \mathrm{~m}$ : measured oxygen consumption; Da- $\mathrm{v}_{2} \mathrm{O}_{2}$ : arteriovenous oxygen difference; oxygen shunt: expressed as a percentage of total blood flow, was calculated during pure oxygen breathing using the Berggren's equation. Inert gas shunt: percentage of blood flow to unventilated lung units; Low $V$ 'A $/ Q$ ': percentage of blood flow to lung units with $V^{\prime} \mathrm{A} / Q^{\prime}$ 'ratios between 0.005 and 0.01 ; Mean $Q^{\prime}$ : mean $V^{\prime} \mathrm{A} / Q^{\prime}$ of blood flow distribution; $\log$ SD $Q^{\prime}: \log$ standard deviation of perfusion distribution; VD/VT: inert gas dead space, expressed as a percentage of total ventilation; Mean $V^{\prime}$ : mean $V^{\prime} \mathrm{A} / Q^{\prime}$ of ventilation distribution; $\log$ SD $V^{\prime} \mathrm{A}: \log$ standard deviation of ventilation distribution.

haemodynamics showed an hyperkinetic profile, with low systemic and pulmonary vascular resistances. A marked intrapulmonary shunt of $31 \%$ was measured using the MIGET, and a similar value was obtained with the $100 \%$ oxygen breathing method. The distribution of ventilation-perfusion ratios was otherwise normal. Despite this right-to-left shunt, and because of high mixed venous oxygen tension $\left(P_{\bar{v}}^{-}, \mathrm{O}_{2}\right)$ and mixed venous oxygen saturation $\left(\mathrm{S}_{\mathrm{v}}^{-} \mathrm{O}_{2}\right)(78 \%), \mathrm{Pa}_{\mathrm{a}} \mathrm{O}_{2}$ was relatively preserved.

Four months after coil embolization, a marked reduction in cardiac index was observed, and intrapulmonary shunting was decreased to $19 \%$. The final net increase in $P \mathrm{a}, \mathrm{O}_{2}$ during room air breathing was $2 \mathrm{kPa}$, whilst $P \overline{\mathrm{v}}, \mathrm{O}_{2}$ and $S_{\mathrm{v}}^{-} \mathrm{O}_{2}(79 \%)$ remained above normal values. Modest increases in $\mathrm{Pa}, \mathrm{O}_{2}$ were observed in the immediate period following coil embolization, suggesting that the rapid symptomatic improvement following the procedure resulted mainly from a haemodynamic effect. In addition, $P \mathrm{a}, \mathrm{O}_{2}$ predicted values from the recovered ventilationperfusion distribution were 8.27 and $10.27 \mathrm{kPa}$ prior to and after coil embolization, respectively.

\section{Discussion}

The association of HHT and PAVM has been clearly documented for many years [7-9], with a marked predominance in middle-aged women $[8,9]$. When PAVM are large or multiple, hypoxaemia develops as a consequence of symptomatic right-to-left intrapulmonary shunting. Reported values for mean intrapulmonary shunts (assessed by the $100 \%$ oxygen breathing technique) vary from $25 \%$ [4] to $44 \%$ [1] of cardiac output, with individual values as high as $66 \%$ of cardiac output [7]. It may be noticed that several authors [1, 3, 4], assuming a normal arteriovenous oxygen difference (i.e. $50 \mathrm{ml} \cdot \mathrm{L}^{-1}$ of blood), have probably underestimated the values of $P_{\mathrm{v}}^{-}, \mathrm{O}_{2}$ and $\mathrm{S}_{\mathrm{v}}^{-} \mathrm{O}_{2}$, and consequently the values of intrapulmonary shunt. Estimating the arteriovenous oxygen difference to $50 \mathrm{ml} \cdot \mathrm{L}^{-1}$ of blood in our patient would have led to calculation of the oxygen shunt at $22 \%$ instead of $32 \%$ of cardiac output.

In the present report, intrapulmonary shunt was precisely determined using two different methods, which showed concordant results. In addition, the predicted values of $\mathrm{Pa}, \mathrm{O}_{2}$ were very close to the measured $\mathrm{Pa}, \mathrm{O}_{2}$. These findings suggest that a diffusion defect was minimal or absent in this patient, and also that shunt was the major determinant of hypoxaemia. Our patient had no associated heart disease, and exhibited a typical hyperkinetic profile, with dramatically increased cardiac index and reduced vascular resistances. Although haemodynamic data have seldom been reported in PAVM, an increased cardiac index (up to $8.59 \mathrm{~L} \cdot \mathrm{min}^{-1} \cdot \mathrm{m}^{-2}$ ) has been noted in 8 of 10 patients [7] and 6 of 9 patients [1] with HHT-associated PAVM. Notably, this haemodynamic profile is very similar to those reported in other pathological conditions, such as hepatic diseases associated with intrapulmonary shunts $[6,10,11]$. In this setting, increased $P_{\mathrm{v}}^{-}, \mathrm{O}_{2}$ and $S_{\bar{v}}^{-} \mathrm{O}_{2}$ associated with a high cardiac output appear to be a major protective mechanism against hypoxaemia [12], as still evidenced in our patient after coil embolization.

Embolization of all visible vascular malformations was followed by a parallel decrease in shunt and cardiac index of 39 and $41 \%$, respectively. In animals or humans with acute lung injury, intrapulmonary shunting has been shown to depend on cardiac output $[13,14]$. It is not clear whether such a mechanism played any role in the present case. Since the reduction of cardiac output observed after embolization was associated with an increase in pulmonary artery pressure $(P \mathrm{pa})$ and $P_{\mathrm{v}, \mathrm{O}_{2}}^{-}$, this should have increased, rather than decreased, intrapulmonary shunt. 
Moreover, in a previous study performed in patients with liver cirrhosis and intrapulmonary shunting, we found that shunt was independent of cardiac output [6]. Similarly, it is unclear whether the decrease in $\mathrm{Pa}, \mathrm{O}_{2}$, observed in the present patient during the exercise test performed after coil embolization, was due to a decrease in $P_{\mathrm{v}}^{-}, \mathrm{O}_{2}$, an increase in shunt, or both. Exercise-induced alterations of gas exchange in patients with PAVM has been variously interpreted, since WHYTE et al. [15] observed an increase in intrapulmonary shunt, whilst PENNINGTON et al. [4] suggested that flow through the PAVM decreases during exercise as a proportion of cardiac output.

The effective occlusion of all visible PAVM was associated with a rapid and major improvement in the exercise capability and daily activities of the patient, contrasting with a moderate and delayed improvement in her resting arterial blood gases. Thus, $\mathrm{Pa}_{\mathrm{a}} \mathrm{O}_{2}$ during short-term follow-up did not accurately reflect the efficacy of therapeutic intervention. The symptomatic improvement observed after embolization was probably related to the marked reduction in cardiac output at rest, which allowed the patient to benefit from a good haemodynamic reserve, useable during exercise.

In addition, gas exchange investigations in our patient indicated that large PAVM, accessible to percutaneous occlusion, accounted for roughly $40 \%$ of intrapulmonary shunting, and that numerous nondetectable malformations still remained open across the pulmonary vascular bed, as observed previously by others $[3,4]$. Thus, $\mathrm{Pa}, \mathrm{O}_{2}$ did not accurately reflect the persistent impairment of gas exchange during medium-term follow-up. Because PAVM associated with HHT have been shown to evolve [9], it may be expected that short and medium-term clinical and gas exchange improvements observed after embolization may not be maintained during long-term follow-up.

We conclude that, in patients with pulmonary arteriovenous malformations, changes in $\mathrm{Pa}, \mathrm{O}_{2}$ are minimized by concomitant alterations in cardiac output, and that a major improvement (or worsening) in exercise capabilities may be associated with only minimal changes in $\mathrm{Pa}, \mathrm{O}_{2}$.

\section{References}

1. Terry PB, White RI, Barth KH, Kaufman SL, Mitchell SE. Pulmonary arteriovenous malformations: physio- logic observations and results of therapeutic balloon embolization. N Engl J Med 1983; 308: 1197-1200.

2. Burke CM, Safai C, Nelson DP, Raffin TA. Pulmonary arteriovenous malformations: a critical update. Am Rev Respir Dis 1986; 134: 334-339.

3. Chilvers ER, Whyte MKB, Jackson JE, Allison DJ, Hughes JMB. Effect of percutaneous transcatheter embolization on pulmonary function, right-to-left shunt, and arterial oxygenation in patients with pulmonary arteriovenous malformations. Am Rev Respir Dis 1990; 142: 420-425.

4. Pennington DW, Gold WM, Gordon RL, Steiger D, Ring E, Golden JA. Treatment of pulmonary arteriovenous malformations by therapeutic embolization. Am Rev Respir Dis 1992; 145: 1047-1051

5. Wagner PD, Salzman HA, West JB. Measurement of continuous distributions of ventilation-perfusion ratios. J Appl Physiol 1974; 36: 588-599.

6. Andrivet P, Cadranel J, Housset B, Herigault R, Harf A, Adnot S. Mechanisms of impaired arterial oxygenation in patients with liver cirrhosis and severe respiratory insufficiency; effects of indomethacin. Chest 1993; 103 : 500-507.

7. Moyer JH, Glantz G, Brest AN. Pulmonary arteriovenous fistulas; physiologic and clinical considerations. Am $J$ Med 1962; 32: 417-435.

8. Dines DE, Seward JB, Bernatz PE. Pulmonary arteriovenous fistulas. Mayo Clin Proc 1983; 58: 176-181.

9. Vase P, Holm M, Arendrup H. Pulmonary arteriovenous fistulas in hereditary hemorrhagic telangiectasia. Acta Med Scand 1985; 218: 105-109.

10. Agusti AGN, Roca J, Bosch J, Garcia-Pagan JC, Wagner PD, Rodriguez-Roisin R. Effects of propranolol on arterial oxygenation and oxygen transport to tissues in patients with cirrhosis. Am Rev Respir Dis 1990; 142: 306-310.

11. Cadranel JL, Milleron BJ, Cadranel J-F, et al. Severe hypoxemia-associated intrapulmonary shunt in a patient with chronic liver disease: improvement after medical treatment. Am Rev Respir Dis 1992; 146: 526-527.

12. Dantzker DR. The influence of cardiovascular function on gas exchange. Clin Chest Med 1983; 4: 149-159.

13. Dantzker D, Lynch J, Weg JG. Depression of cardiac output is a mechanism of shunt reduction in the therapy of acute respiratory failure. Chest 1980; 77: 636-642.

14. Freden F, Cigarini I, Mannting F, Hagberg A, Lemaire F, Hedenstierna G. Dependence of shunt on cardiac output in unilobar oleic acid edema; distribution of ventilation and perfusion. Intensive Care Med 1993; 19: 185190.

15. Whyte MKB, Peters AM, Hughes JMB. Quantification of right-to-left shunt at rest and during exercise in patients with pulmonary arteriovenous malformations. Thorax 1992; 47: 790-796. 